\title{
ВЛИЯНИЕ УГОЛЬНОЙ ПЫЛИ НА ЭКОЛОГИЮ И ЗДОРОВЬЕ ЧЕЛОВЕКА (НА ПРИМЕРЕ ГОРОДА МУРМАНСКА)
}

\author{
Константинов Артём Юрьевич \\ Культенко Валентин Петрович \\ студенты 1 курса кафедры \\ биологии и водных биоресурсов \\ Научный руководитель: Петрова Людмила Анатольевна \\ к.т.н., доцент кафедры химии \\ ФГАОУ ВО «Мурманский государственный \\ технический университет»
}

\begin{abstract}
Аннотация: Проблема антропогенного загрязнения в условиях деятельности Мурманского морского торгового порта является одной из актуальных и влияет на здоровье человека и экологию местности. Снежный покров отражает степень антропогенного воздействия на окружающую среду, так как способен накапливать и сохранять вещества, поступающие с зимними осадками, что позволяет провести оценку поступления токсикантов в почвы [3, с. 23]. Целью исследования является анализ влияния угольной пыли на экологию и здоровье человека.
\end{abstract}

Ключевые слова: угольная пыль, окружающая среда, экология, токсические примеси, снежный покров, анализ.

\section{ENVIRONMENTAL AND HEALTH IMPACTS OF COAL DUST (CASE OF MURMANSK)}

\section{Konstantinov Artem Yurievich Kultenko Valentin Petrovich}

\begin{abstract}
The problem of man-made pollution in the context of the activities of the Murmansk seaport is one of the current problems affecting human health and the ecology of the area. Snow cover reflects the degree of anthropogenic impact on the environment, as it is able to accumulate and retain substances from winter precipitation, which allows estimation of toxic inputs into the soil [3, p. 23]. The aim of the study was to analyse the environmental and health effects of coal dust.
\end{abstract}


Key words: coal dust, environment, ecology, toxic impurities, snow cover, analysis.

С 2020 года пыль каменного угля относится к классу загрязняющих веществ. Черный налет на снежном покрове и на окнах мурманчан - не редкость. Причина - работа Мурманского морского торгового порта. Согласно статистике, 95\% грузооборота которого приходится на уголь. Известно, что его обработка происходит открытым способом.

Был проведен экологический мониторинг снежного покрова, поскольку он является индикатором загрязнения атмосферного воздуха. Для забора материала выделено 5 объектов в Ленинском и Первомайском округах Мурманска, а также на противоположном от города берегу Кольского залива (р-н Абрам-Мыс). С исследуемых участков было взято 15 образцов снежного покрова для органолептического и физико-химического анализа.

Таблица 1

Точки отбора снеговых проб

\begin{tabular}{|c|c|}
\hline $\begin{array}{c}\text { № объекта } \\
\text { отбора } \\
\text { проб }\end{array}$ & Описание места отбора \\
\hline 1 & $\begin{array}{c}\text { Мурманск, сопка Зелёный Мыс, р-н памятника Защитам Советского } \\
\text { Заполярья, } 1 \text { м от тротуара. Прилегающая территория покрыта газоном и } \\
\text { древесной растительностью. Удаленность от Мурманского морского } \\
\text { торгового порта } 1.63 \text { км. }\end{array}$ \\
\hline 2 & $\begin{array}{l}\text { Мурманск, ул. Чумбарова-Лучинского, центральная магистраль } \\
\text { городского значения, } 1 \text { м от тротуара, } 15 \text { м от проезжей части. } \\
\text { Прилегающая территория покрыта древесной растительностью. } \\
\text { Удаленность от Мурманского морского торгового порта 4,4 км. }\end{array}$ \\
\hline 3 & $\begin{array}{c}\text { КПП Мурманского морского торгового порта. Мурманск, Портовый } \\
\text { проезд, 22. 0,5 м от тротуара, 2,0 м от проезжей части }\end{array}$ \\
\hline 4 & $\begin{array}{c}\text { Мурманск, Долина Уюта, д. 3, 2,0 м от тротуара. Прилегающая территория } \\
\text { покрыта газоном и древесной растительностью. Удаленность от } \\
\text { Мурманского морского торгового порта } 6,0 \text { км }\end{array}$ \\
\hline 5 & $\begin{array}{c}\text { Мурманск, р- н Абрам Мыс, Охотничий переулок, д.6, } 1 \text { м от тротуара, } \\
15 \text { м от проезжей части, } 10 \text { м. от жилой застройки. Прилегающая } \\
\text { территория покрыта древесной растительностью Удаленность от } \\
\text { Мурманского морского торгового порта 1,69 км }\end{array}$ \\
\hline
\end{tabular}

На вышеназванных объектах были обследованы отдельные участки, где был произведен отбор проб снега (табл. 1). В качестве условно-фоновой территории был выбран экспериментальный участок в районе Абрам-Мыса, расположенный на значительном расстоянии от источников загрязнения. 
Отбор проб снега производился в конце ноября - начале декабря 2021 г. В растворах, полученных от разложения твердого остатка на фильтре, определяли микрокомпоненты ( $\mathrm{Ni}, \mathrm{Cu}, \mathrm{Cr})$ методом тест-систем никель, медь и хром. Образцы талой воды исследованы при помощи методик количественного и качественного химического анализа воды, были определены $\mathrm{pH}$ и макрокомпоненты (Fe (II), $\mathrm{Fe}(\mathrm{III}), \mathrm{SO}_{4}, \mathrm{SO}_{3}, \mathrm{Cl}, \mathrm{NH}_{(4)}$.

\section{3. Результаты исследований.}

Анализ годовых отчетов АО «Мурманский морской торговый порт»отчёт по перевалке угля за 2018-2020 годы и Министерства здравоохранения Мурманской области - отчёт по заболеваемости болезнями легких и онкологическими заболеваниями жителей Мурманска за 2018-2019 годы показал, что происходит ежегодное увеличение объема перевалки угля, а снижение заболеваемости связано, вероятно, с высоким уровнем миграции мурманчан в другие регионы.

Перевалка угля. Анализ итоговых показателей на основе годовых отчетов АО «Мурманский морской торговый порт» - отчёт по перевалке угля за 2018-2020 годы (рис. 1).

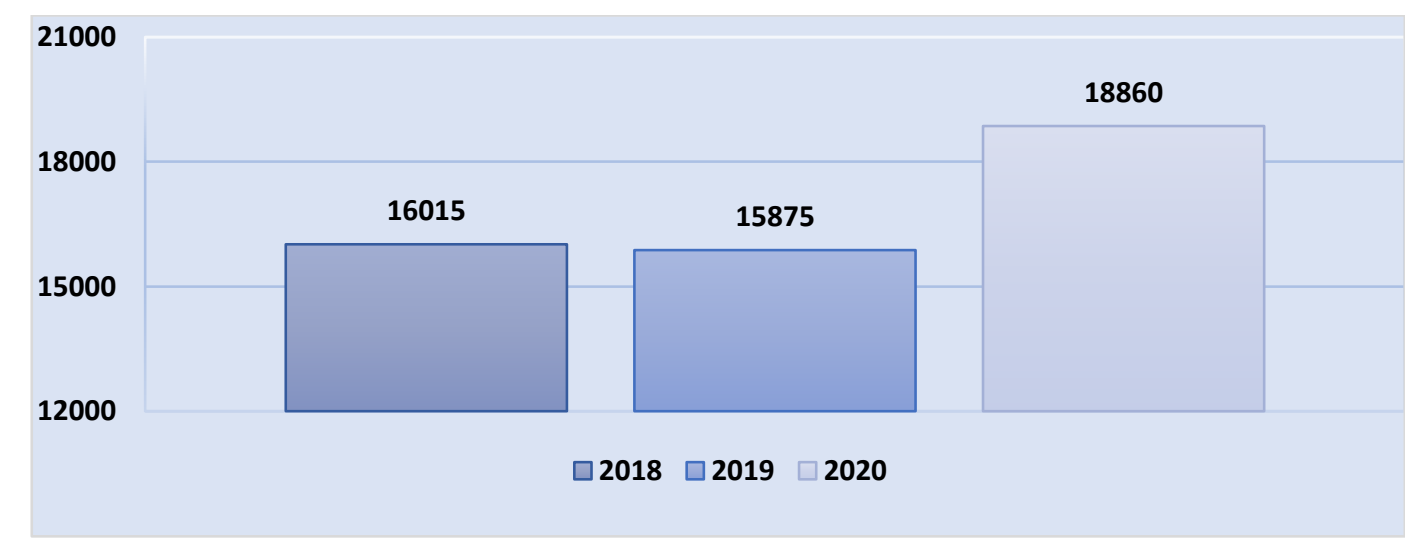

Рис. 1. Перевалка угля в «Мурманском морском торговом порту» по итогам 2018, 2019, 2020 гг. (тыс. тонн).[5]

С 2018 по 2020 год среднесуточная выгрузка составила более 600 вагонов/сутки [5]. Таким образом, наблюдается тенденция к увеличению перевалки угля с 2018 года.

Заболеваемость. На основе ежегодных данных статистики Министерства здравоохранения Мурманской области изучены показатели по заболеваемости болезнями легких и онкологическими заболеваниями жителей Мурманска 
за 2018-2019 годы. Анализ заболеваемости за 2020-2021 годы не производился из-за последствий новой коронавирусной инфекции COVID-19.

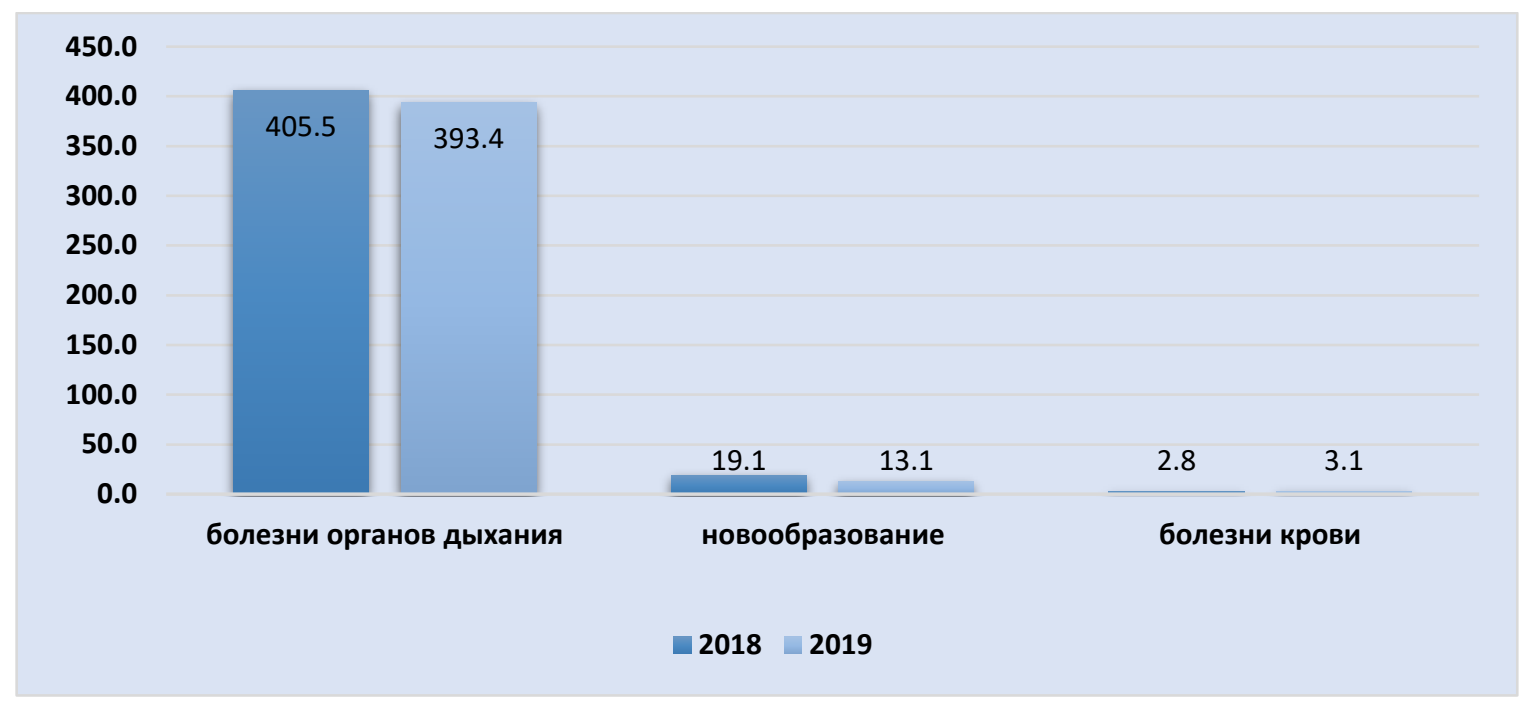

Рис. 2. Средние показатели заболеваемости населения Мурманской области за 2018-2019 гг. (данные приведены на 1000 человек населения) [6]

Таким образом, учитывая, что перевалка угля имеет ежегодный рост показателей и то, что используется открытый метод транспортировки и отгрузки каменного угля, высока вероятность роста заболеваемости жителей Мурманска и степени загрязненности окружающей среды.

\section{Органолептический анализ снежного покрова}

При первичном визуальном осмотре дана характеристика снежного покрова на объектах отбора проб. Результаты органолептического анализа представлены в таблице № 1 .

Таблица 2

Состояние снежного покрова на пробных площадках

(внешнее состояние)

\begin{tabular}{|c|c|c|c|c|c|c|c|}
\hline $\begin{array}{c}\text { № } \\
\text { объекта }\end{array}$ & $\begin{array}{c}\text { Мощность } \\
\text { слоя, см }\end{array}$ & $\begin{array}{c}\text { Вид } \\
\text { снега }\end{array}$ & $\begin{array}{c}\text { Цвет } \\
\text { снега }\end{array}$ & Влажность & Твердость & $\begin{array}{c}\text { Наличие } \\
\text { мусора на } \\
\text { поверхности }\end{array}$ \\
\hline 1 & 20 & 15 & $\begin{array}{c}\text { мелко- } \\
\text { зернистый }\end{array}$ & $\begin{array}{c}\text { беловато } \\
\text {-серый }\end{array}$ & влажный & мягкий & $\begin{array}{c}\text { пылевидный } \\
\text { налёт }\end{array}$ \\
\hline
\end{tabular}


Продолжение таблицы 2

\begin{tabular}{|c|c|c|c|c|c|c|c|}
\hline 2 & 20 & 10 & $\begin{array}{c}\text { ледяная } \\
\text { корка, } \\
\text { мелкозернистый }\end{array}$ & серый & сухой & твердый & $\begin{array}{c}\text { пылевидный } \\
\text { налёт }\end{array}$ \\
\hline 3 & 20 & 10 & $\begin{array}{c}\text { ледяная } \\
\text { корка, } \\
\text { крупнозернистый }\end{array}$ & $\begin{array}{c}\text { темно- } \\
\text { серый }\end{array}$ & сухой & твердый & $\begin{array}{c}\text { пылевидный } \\
\text { налёт }\end{array}$ \\
\hline 4 & 20 & 10 & $\begin{array}{c}\text { ледяная } \\
\text { корка, } \\
\text { мелкозернистый }\end{array}$ & серый & сухой & твердый & $\begin{array}{c}\text { пылевидный } \\
\text { налёт }\end{array}$ \\
\hline 5 & 20 & 20 & $\begin{array}{c}\text { мелкозернистый } \\
\text { селовато } \\
\text {-серый }\end{array}$ & сухой & мягкий & $\begin{array}{c}\text { пылевидный } \\
\text { налёт }\end{array}$ \\
\hline
\end{tabular}

Объект отбора проб №1. Дата: 20 ноября 2021 года. Цвет снега беловато-серый. Мягкий, влажный, мелкозернистый. Размеры шурфа: 20х15 см. На поверхности снежного покрова находился тонкий слой пыли.

Объект отбора проб №2. Дата: 23 ноября 2021 года. Цвет снега - серый. Сухой, твердый, наличие ледяной корки, под ней мелкозернистый снег. Размеры шурфа: 20x10 см. На поверхности снежного покрова находился слой пыли.

Объект отбора проб №3. Дата: 23 ноября 2021 года. Цвет снега тёмно-серый. Сухой, твердый, наличие ледяной корки, под ней крупнозернистый снег. Размеры шурфа: 20x10 см. На поверхности снежного покрова находился толстый слой пыли.

Объект отбора проб №4. Дата: 28 ноября 2021 года. Цвет снега - серый. Сухой, твердый, ледяная корка, под ней мелкозернистый снег. Размеры шурфа: $20 x 10$ см. На поверхности снежного покрова пылевидный налёт.

Объект отбора проб №5. Дата: 03 декабря 2021 года. Цвет снега беловато-серый. Сухой, мягкий, мелкозернистый снег с пылевидным налётом. Размеры шурфа: 20х20 см.

Всего с участков отбора проб собрано 15 образцов снежного покрова для качественного и химического анализа.

\section{Оценивание химического состава образцов талой воды.}

Результаты химического состава талых снеговых вод представлены в таблице № 3 .

\section{Макрокомпоненты в образцах снежного покрова (талой воде).}

Чистый снег, как и чистая дождевая вода, имеет $\mathrm{pH}=5,6$. На основании полученных данных реакция среды характеризуется как щелочная. Слабая кислотность и нейтральная среда в пробах обусловлена присутствием в атмосфере значительного содержания аммиака, угольной пыли и оксидов металлов. Таким образом, в обследуемых районах наблюдается подщелачивание снежного покрова. 
Таблица 3

Физико-химический анализ и определение рН талой воды

\begin{tabular}{|c|c|c|c|c|c|}
\hline $\begin{array}{c}\text { № объектов } \\
\text { Вещества }\end{array}$ & 1 & 2 & 3 & 4 & 5 \\
\hline $\mathrm{pH}(\mathrm{N}=5,6)$ & 6,1 & 6,5 & 6,9 & 7,1 & 5,8 \\
\hline Никель тест, мг/л & 0 & 3 & 5 & 0 & 0 \\
\hline Хромат тест , мг/л & 3 & 0 & 0 & 3 & 3 \\
\hline Купрум тест, мг/л & 5 & 5 & 15 & 30 & 5 \\
\hline ионы Fe $\mathrm{Fe}^{2+}$ & 0 & 2 & 0 & 3 & 0 \\
\hline ионы $\mathrm{Fe}^{3+}$ & 3 & 0 & 4 & 0 & 2 \\
\hline сульфат-иона $\mathrm{SO}_{4}{ }^{2-}$ & + & + & + & + & + \\
\hline сульфит-иона $\mathrm{SO}_{3}^{2-}$ & - & + & + & - & + \\
\hline хлорид-иона $\mathrm{Cl}^{-}$ & + & + & + & + & + \\
\hline ионы $\mathrm{NH}_{4}{ }^{+}$ & - & - & - & + & - \\
\hline
\end{tabular}

В снеге наблюдается присутствие основных анионов $\mathrm{SO}_{4}{ }^{2-}, \mathrm{SO}_{3}{ }^{2-}, \mathrm{Cl}^{-}, \mathrm{NH}_{4}{ }^{+}$. Наличие хлорид-ионов во всех образцах объясняется использованием антигололедных смесей. Источниками ионов $\mathrm{NH}_{4}{ }^{+}, \mathrm{SO}_{4}{ }^{2-}, \mathrm{SO}_{3}{ }^{2-}$ могут быть продукты окисления атмосферного азота золы городских котельных и угольной пыли, которые распространяется благодаря направлению ветров, а также солевом загрязнении улиц.

\section{Микроэлементы в образцах снежного покрова (талой воде)}

Наличие и концентрации микрокомпонентов в талой снеговой воде представлены в таблице № 3. Концентрации $\mathrm{Ni}$ в жидкой фазе снега варьируют от 3 до 5 мг/л в образцах № 2 и 3. Концентрация меди обнаружена во всех образцах, а диапазон значений варьируется от 5 до 30 мг/л. Данные хрома обнаружены в образцах № 2 и 3, их концентрация составляет от 3 до 5 мг/л. Ионы металлов $\mathrm{Fe}^{2+}$ для снежного покрова (в жидкой фазе) характерно улиц Мурманска с наиболее плотным автомобильным движением и $\mathrm{Fe}^{3+}$ обусловлено техногенным загрязнением.

Таким образом, загрязнение снежного покрова вызвано в первую очередь пылью техногенного происхождения, которая накапливает в себе вредные примеси. 


\section{Анализ количественных показателей пыли}

После окончания фильтрования талой воды, фильтры с осадком были высушены и взвешивались на лабораторных весах для определения массы пыли. Расчёт запыленности территории рассчитывался, учитывая объем талой воды, по формуле:

количество пыли на кг снега = масса осадка • 500/объем талого снега

Полученные результаты представлены в таблице № 4.

Таблица № 4

Объем талого снега и масса пыли

\begin{tabular}{|c|c|c|c|}
\hline $\begin{array}{c}\text { № } \\
\text { объекта }\end{array}$ & $\begin{array}{c}\text { Объём талого } \\
\text { снега, . }\end{array}$ & $\begin{array}{c}\text { Масса пыли, } \\
\text { мг/л }\end{array}$ & $\begin{array}{c}\text { ПДК } \\
<\mathbf{1} \text { мг\л }\end{array}$ \\
\hline 1 & 0,5 & 7,2 & \\
\hline 2 & 0,5 & 23,8 & \\
\hline 3 & 0,5 & 35,8 & \\
\hline 4 & 0,5 & 26,9 & \\
\hline 5 & 0,5 & 4,6 & \\
\hline
\end{tabular}

Вес пыли в осадке на фильтре превышает значения ПДК. Плотный пылевой слой, который остается на почвах после таяния, оказывает губительное влияние на жизнедеятельность растений, при условии ветреной и сухой погоды поднимается в воздух и негативно сказывается на здоровье населения, вызывая заболевания органов дыхания и онкологические заболевания.

\section{Органолептический анализ проб талого снега}

Для определения запаха проанализировано 500 мл талой воды комнатной температуры каждого образца.

В пробах талой воды, взятых на площадках № 2 и № 4, ощущался заметный химический запах, в пробе, взятой на площадке № 3 , имелся сильный химический запах. Проба №1 и №5 - слабый землистый запах. Интенсивность запаха была определена в результате нагрева на водяной бане до температуры 60 градусов. 
Таблица 5

Определение мутности, цвета и характерного запаха талой воды

\begin{tabular}{|c|c|c|c|c|c|}
\hline $\begin{array}{l}\text { № } \\
\Pi / \Pi\end{array}$ & $\begin{array}{c}\text { Вид } \\
\text { до фильтрации }\end{array}$ & $\begin{array}{c}\text { Вид } \\
\text { после } \\
\text { фильтрации } \\
\end{array}$ & Мутность & Запах & Осадок \\
\hline 1 & $\begin{array}{l}\text { серо-желтый, } \\
\text { прозрачный }\end{array}$ & $\begin{array}{c}\text { незначительные } \\
\text { оттенки серого } \\
\text { цвета, } \\
\text { прозрачный } \\
\end{array}$ & +++ & $\begin{array}{c}\text { слабый } \\
\text { землистый } \\
\text { запах }\end{array}$ & $\begin{array}{c}\text { осадок черного } \\
\text { цвета } \\
\text { (угольные частицы, } \\
\text { пыль) } \\
\end{array}$ \\
\hline 2 & $\begin{array}{c}\text { мутный, серый } \\
\text { с осадком }\end{array}$ & $\begin{array}{l}\text { серый цвет, } \\
\text { слегка мутный }\end{array}$ & +++ & $\begin{array}{c}\text { заметный } \\
\text { химический } \\
\text { запах }\end{array}$ & $\begin{array}{c}\text { осадок черного } \\
\text { цвета (угольные } \\
\text { частицы, пыль) }\end{array}$ \\
\hline 3 & $\begin{array}{c}\text { мутный, } \\
\text { темно-серый } \\
\text { со значительным } \\
\text { осадком }\end{array}$ & $\begin{array}{c}\text { серый цвет, } \\
\text { мутный }\end{array}$ & +++ & $\begin{array}{c}\text { сильный } \\
\text { химический } \\
\text { запах }\end{array}$ & $\begin{array}{c}\text { осадок черного } \\
\text { цвета с черными } \\
\text { угольными } \\
\text { частицами и } \\
\text { песком, пыль }\end{array}$ \\
\hline 4 & $\begin{array}{c}\text { мутный, серый } \\
\text { с осадком }\end{array}$ & $\begin{array}{c}\text { серый цвет, } \\
\text { слегка мутная }\end{array}$ & +++ & $\begin{array}{c}\text { заметный } \\
\text { химический } \\
\text { запах }\end{array}$ & $\begin{array}{c}\text { серо-коричневый } \\
\text { осадок (угольные } \\
\text { частицы, пыль, } \\
\text { песок) }\end{array}$ \\
\hline 5 & $\begin{array}{c}\text { прозрачный, } \\
\text { бледно-желтый с } \\
\text { незначительным } \\
\text { осадком }\end{array}$ & слегка мутная & + & $\begin{array}{c}\text { слабый } \\
\text { землистый } \\
\text { запах }\end{array}$ & $\begin{array}{c}\text { незначительный } \\
\text { осадок в виде } \\
\text { мелких частиц }\end{array}$ \\
\hline
\end{tabular}

Цвет проб талого снега до фильтрации варьируется от серо-желтого до темно-серого с наличием осадка, содержащего угольные частицы, пыль, песок. Степень мутности талой воды зависит от района сбора образцов, включающих в себя примесями техногенными характера. Образцы снежного покрова, взятые на удалении от антропогенных загрязнителей, в том числе и Мурманского морского торгового порта, до и после фильтрации имеют слабую степень загрязнения.

Таким образом, во всех образцах присутствуют частицы угольной пыли. Их количество нарастает по мере приближения к Мурманскому морского торговому порту.

\section{Выводы.}

В результате физико-химического анализа проб снежного покрова установлено, что во всех пробах имеется превышение $\mathrm{pH}$ нормы (от 5,8 - 7,1). Подщелачивание снежного покрова оксидами металлов происходит благодаря автомобильным выхлопам и угольной пыли, накапливающей их. Согласно 
качественному и количественному анализу обнаружено: в пробах № 2,3 наличие $\mathrm{Ni}$ - 3,0 и 5,0 мг/л; № 1,4,5 - Cr- 3,0 мг/л; Cu во всех образцах, наибольшее её содержание в пробе № 4-30 мг/л. Качественный анализ показал наличие ионов железа (II) в образцах № 2,4, а также железа (III) — № 1,3,5. Концентрация железа превышает ПДК. Во всех образцах обнаружены хлорид ионы и сульфат-ионы. Соли аммония обнаружены в образце № 4.

Macca пыли во всех образцах превышает ПДК. Наибольшее значение обнаружено в образце № 3 и составляет 35,8 мг/л, а наименьшее в образце № 5 $-4,6$ мг/л.

Анализируя результаты исследования, можно сделать вывод, что угольная пыль, присутствовавшая во всех образцах исследования, содержит токсичные примеси (ионы тяжелых металлов и кислот), которые ухудшают экологическую обстановку города Мурманска и влияют на здоровье жителей.

\section{Список литературы}

1. Климов С.А. Угольная промышленность и энергетическая безопасность стран мира. 2001 г. - 288 с.

2. Третьякова М.О. Угольная отрасль России. Экспорт угля и экологические проблемы //Экология и безопасность жизнедеятельности. - 2019 - № 10 - C. 100-105.

3. Зарина Л.М., Гильдин С.M. Геоэкологический практикум: Учебно-методическое пособие. - СПб.: Изд-во РГПУ им. А. И. Герцена, 2011. $-60 \mathrm{c}$.

4. Морские вести России\ [Электронный ресурс]: http://www.morvesti.ru/ analitika/1688/89445】(дата обращения: 20.11.2021).

5. Новости Портньюс: «Мурманский МТП планирует заменить долю угля железорудным сырьем» [Электронный ресурс]: https:/portnews.ru/news/ 301207/( дата обращения: 22.12.2021).

6. Федеральная служба государственной статистики〉[Электронный pecypc]:https://murmanskstat.gks.ru/storage/mediabank/B6AxWGtZ/01001_2020.pd f\(дата обращения:23.12.2021).

7. Морские вести России. [Электронный ресурс]: http://www.morvesti.ru/ analitika/1688/89445】(дата обращения: 20.11.2021). 